ISSUES IN PUBLIC HEALTH

\title{
Low levels of physical activity in female adolescents cause overweight and obesity: Are our schools failing our children?
}

\author{
M N Mokabane, M M Mashao, M van Staden, M J Potgieter, A Potgieter \\ Nelly Mokabane is an MSc student in the Department of Physiology and Environmental Health, School of Molecular and Life Sciences, University of \\ Limpopo, South Africa; Mercy Mashao is a junior lecturer in the Department, and currently registered for an MSc degree in Physiology; Marlise van \\ Staden, PhD, is a senior lecturer in the Department, with a keen interest in obesity, and its causes and effects; Martin Potgieter, PhD, is an associate \\ professor in the Department of Biodiversity, School of Molecular and Life Sciences, University of Limpopo; and Annelize Potgieter is manager of the \\ Science Centre at the University of Limpopo.
}

Corresponding author: $M$ van Staden (marlise.vanstaden@ul.ac.za)

The increasing prevalence of overweight and obesity among female adolescents is a global health problem. In developing countries such as South Africa, this increase is often associated with urbanisation and the adoption of a Western lifestyle. Two aspects of the Western lifestyle that contribute to the development of overweight and obesity are a decrease in physical activity levels and an increase in the consumption of energy-dense food, high in fats and refined sugar. Information on the prevalence of increased body fatness in populations in transition is scarce, but necessary for effective planning and intervention. Current indications are that there is a trend towards unhealthy behaviour among high-school girls, globally and in South Africa. Schools can play an important role in the prevention of overweight and obesity among schoolgirls. It is recommended that school governing bodies institute remedial action to prevent weight gain in children, especially girls.

S Afr Med J 2014;104(10):665-667. DOI:10.7196/SAMJ.8577

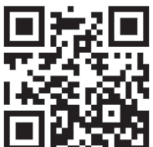

Obesity develops rapidly during adolescence. ${ }^{[1]}$ According to the World Health Organization (WHO), childhood obesity is a major global public health problem. ${ }^{[2]}$ The prevalence of overweight and obesity is increasing rapidly in Africa; between 1990 and 2010, the number of overweight or obese children doubled. ${ }^{[3]}$ Armstrong et al. ${ }^{[4]}$ noted that there was an increase in overweight and obesity in South Africa (SA) from 1994 to 2004. According to the WHO, ${ }^{[5]}$ females are more likely to be obese than males. This is especially true for black females in SA, who according to Martorell et al. ${ }^{[6]}$ are often overweight or obese, or have abdominal obesity. In African culture increased body fatness is viewed as a sign of health and wealth. Mothers therefore tend to over-feed their infants, thereby increasing the risk of developing obesity. ${ }^{[7]}$

Although traditional culture remains strong in many parts of SA, a transition is currently occurring between traditional and Westernorientated lifestyles. ${ }^{[8]}$ This has potential consequences for overweight and obesity among black schoolchildren, especially girls, who live in periurban and urban environments. Their increase in body fatness increases the risk of development of chronic diseases of lifestyle such as hypertension, stroke, coronary heart disease and type 2 diabetes mellitus. ${ }^{[9]}$

\section{Possible causes for increased body fatness in schoolgirls}

Since increased body fatness is a consequence of a positive energy balance, ${ }^{[10]}$ schoolgirls who use less energy than they consume will gradually become overweight and eventually obese. The two most obvious causes of increased body fatness in schoolgirls are probably a decrease in physical activity and an increased consumption of energy, both of which are associated with urbanisation and westernisation. ${ }^{[11]}$
Life in an urban setting has a severe negative impact on the amount of physical activity a child has the chance to enjoy. ${ }^{[12]}$ In urban and periurban regions, safety concerns contribute to the decrease in physical activity, ${ }^{[11]}$ e.g. it is no longer safe for children to walk to school or to play in parks. Finances also contribute to the decreased physical activity level in children, ${ }^{[11]}$ many parents lacking the money to allow their children to participate in organised sport activities. Periurban communities often lack access to sports facilities in any case, and few schools in these environments have such facilities. ${ }^{[1]}$ The result is that children grow up in an environment that is conducive to sedentary rather than physical activities.

The typical Western diet is high in energy-dense foods, fat and refined sugar ${ }^{[10]}$ that easily lead to a positive energy balance. This is especially true in the presence of decreased physical activity. During the process of urbanisation and westernisation, children (and adults) consume more snacks and convenience foods, which are very high in salt, fat, refined sugar and energy. ${ }^{[13]}$ Part of the problem may be that the SA public is continually confronted with misleading and confusing dietary information. ${ }^{[10]}$ Parents may not know what constitutes a healthy diet, or of the dangers associated with an unhealthy diet and the resultant increase in body fatness. Many public schools have feeding or nutrition programmes, where children receive at least one meal per day at school. The meals are prepared at the school and the menu is often determined by what is available, rather than what constitutes a healthy diet. Another factor contributing to childhood obesity is the foods sold at the school snack shop, ${ }^{[13]}$ which for many schools is an opportunity to increase income. The selection of snacks tends to be based on popularity rather than dietary benefit.

Urbanisation and westernisation in SA are therefore setting the stage for an increasing prevalence of overweight and obesity in 
schoolchildren, with the associated risks of development of a variety of chronic diseases of lifestyle. ${ }^{[10]}$

\section{Case study}

We recently undertook a study at a high school in a periurban area of the Polokwane Local Municipality, Limpopo Province. The study population comprised 56 black girls cally selected to participate in the study, any girl who brought back a consent form signed by her parents/guardian being allowed to take part. Each girl also received a questionnaire (with questions on physical activity and snacking behaviour) that the parents/guardian completed. The weight and height of each girl was measured according to the internationally accepted methods described by Marfell-Jones et al. ${ }^{[14]}$ The body mass index (BMI) was calculated using the formula $\mathrm{kg} / \mathrm{m}^{2}$.

Table 1 shows that the girls consumed significant quantities of snacks (such as aged $13-19$ years. They were not specifi-

sweets, biscuits and cake), between one and seven times per week, and beverages (e.g. cold drink or fruit juice), between two and six times per week. In addition, on average they spent a significant amount of time each day performing sedentary activities (refer to Table 1 for a list), and spent very little time being physically active (Table 1).

Fig. 1 shows the percentages of girls who fell into each of the BMI categories (as suggested by Reilly $\left.{ }^{[15]}\right)$. Of the girls, $67.8 \%$ had a normal BMI $\left(>25 \mathrm{~kg} / \mathrm{m}^{2}\right), 12.5 \%$ were overweight and $3.6 \%$ were obese. The prevalence of overweight and obesity in this young female population is a cause for concern, because overweight in adolescents frequently continues into adulthood. The longer these girls are exposed to the increased body fat, the higher their risk of developing complications later in life. ${ }^{[16]}$ Just over $16.1 \%$ of the girls were underweight/lean. The causes of underweight are usually poor nutrition or malnutrition and infections. ${ }^{[8,17]}$ We did not investigate the causes for underweight in this study.

Table 1. Data on the study population

\begin{tabular}{ll}
\hline Variables, mean (SD) & \\
\hline Age (years) & $15.4(1.9)$ \\
Sweets such as chocolate bars, biscuits and cakes ( $n$ /week) & $3.6(2.9)$ \\
Any form of cold drink or fruit juice ( $n /$ week) & $3.6(2.0)$ \\
Sedentary activities* (hours/day) & $2.0(1.3)$ \\
Physical activities at home ${ }^{\dagger}$ (hours/day) & $1.2(1.5)$ \\
Participating in organised sports (hours/day) & $1.1(1.1)$ \\
Weight (kg) & $54.0(11.6)$ \\
$\begin{array}{l}\text { Height (m) } \\
\text { BMI }\end{array}$ & $1.56(0.06)$ \\
$\begin{array}{l}\text { SD }=\text { standard deviation; BMI = body mass index }\left(\mathrm{kg} / \mathrm{m}^{2}\right) . \\
{ }^{*} \text { Watching television, DVDs or videos; playing video games or cellphone games; using the computer/internet, e.g. to e-mail or } \\
\text { chat online; reading and doing homework. } \\
\text { 'Playing, running around outside, climbing trees, kicking balls, riding a bicycle, swimming. }\end{array}$ & $21.9(3.7)$
\end{tabular}

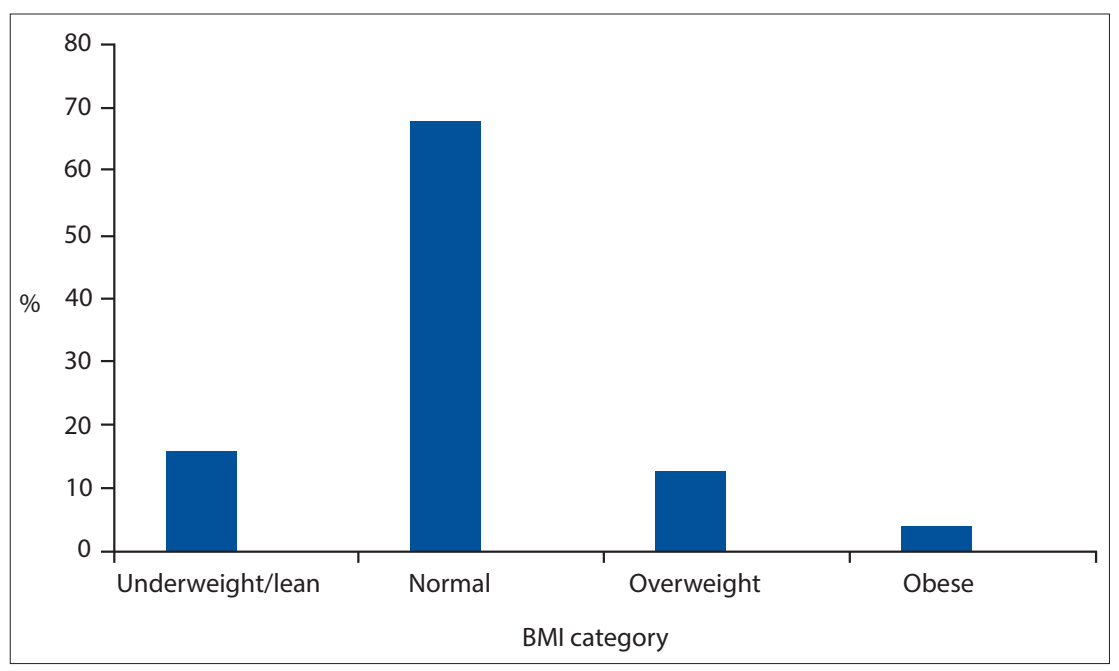

Fig. 1. Percentages of the girls in specific BMI categories. (BMI = body mass index.)
There was a negative but weak correlation $(p=0.017)$ between age and being physically active at home, indicating that as these girls grow older, their physical activity levels decrease. This may be one of the causes for the strong positive correlation between age and BMI $(p=0.001)$, as well as the weak negative correlation between BMI and time spent being physically active at home $(p=0.41)$, and between BMI and participation in sport $(p=0.009)$. There were also weak positive correlations between watching television and frequency of consuming sweets $(p=0.13)$ and soft drinks $(p=0.20)$, indicating that watching television is associated with snacking behaviour. Furthermore, there was a weak positive correlation between time spent playing electronic games and watching television $(p=0.009)$ and frequency of consuming sweets, biscuits and cakes $(p=0.009)$, once again indicating the occurrence of unhealthy behaviours in the same girls.

\section{What do we need to do?}

The girls in our study were not selected on the grounds of their unhealthy behaviour. The behavioural trends they displayed are probably typical of girls in this age group. Taking into consideration that children spend a considerable amount of time at school, schools can play a very important role in promoting regular physical activity and the consumption of a healthy diet. It is recommended that schools introduce and promote sustained healthy physical activities during and after school hours via sports activities to counteract overweight and obesity, especially in girls. The establishment of safe community playgrounds would go a long way towards encouraging physical activity. Ideally, the above should be supplemented by counselling for weight loss and weight management in overweight and obese children. Furthermore, emphasis in the school curriculum must be placed on the health benefits of physical activity and a prudent diet. School snack shops should provide healthy alternatives to sweets and biscuits or cake.

Acknowledgements. The principal, teachers and children at the secondary school are acknowledged for participating in the study. We also thank Dr V O Onywera for permission to use his questionnaire.

\footnotetext{
Dietz WH. Critical periods in childhood for the development of obesity. Am J Clin Nutr 1994;59(5):955-959.

2. Anrig CDC. The obese child. Dynamic Chiropractic 2003;21(22):27-31.

3. De Onis M, Blossner M. Prevalence and trends of overweight among preschool children in developing countries. Am J Clin Nutr 2000;72(4):1032-1039.
} 
4. Armstrong MEG, Lambert MI, Lambert EV. Secular trends in the prevalence of stunting, overweigh and obesity among South African children (1994-2004). Eur J Clin Nutr 2011:65(7):835-840. [http dx.doi.org/10.1038/ejcn.2011.46]

5. World Health Organization. Obesity: Preventing and Managing the Global Epidemic. Report of WHO Consultation. Geneva: WHO, 2000:252

6. Martorell R, Khan LK, Hughes ML, Grummer-Strawn LM. Obesity in women from developing countries. Eur J Clin Nutr 2000;54(3):247-252. [http://dx.doi.org/10.1038/sj.ejcn.1600931]

7. Mamabolo RL, Alberts M, Steyn NP. Prevalence and determinants of stunting and overweight in 3 year old black South African children residing in the central region of Limpopo Province, South Afric Public Health Nutr 2005;8(5):501-508. [http://dx.doi.org/10.1079/PHN2005786]

8. Tathiah N, Moodley I, Mubaiwa V, Denny L, Taylor M. South Africa's nutritional transition Overweight, obesity, underweight and stunting in female primary school learners in rural KwaZulNatal, South Africa. S Afr Med J 2013;103(10):718-723. [http://dx.doi.org/10.7196/SAMJ.6922]

9. Kruger HS, Venter CS, Vorster HH. Obesity in African women in the North West province, Sout Africa is associated with an increased risk of non-communicable diseases: The THUSA study. Br J Nutr 2001;86(6):733-740. [http://dx.doi.org/10.1079/BJN2001469]

10. Vorster HH, Badhan JB, Venter CS. An introduction to the revised food-based dietary guidelines for South Africa. South African Journal of Clinical Nutrition 2013;26(3, Suppl):S5-S12.

1. Botha CR, Wright HH, Moss SJ, Kolbe-Alexander TL. Be active! Revising the South African food base dietary guideline for activity. South African Journal of Clinical Nutrition 2013;26(3, Suppl):S18-S27.
12. Onywera VO, Adamo KB, Sheel AW, et al. Emerging evidence of the physical activity transition in Kenya. Journal of Physical Activity and Health 2012;9(4):554-562

evention: Creating school environments and policies to promote healthy eating and physical activity. Milbank Q 2009;87(1):71-100. [http://

4. Marfell-Jones M, Olds TS, Carter JEL. International Standards for Anthropometric Assessment Underdale, Australia: International Society for the Advancement of Anthropometry, 2006:57-59.

15. Reilly JJ. Assessment of obesity in children and adolescents: Syntheses of recent systematic reviews and clinical guidelines. J Hum Nutr Diet 2010,23(3).205-211. [http://dx.doi.org/10.1111/j.1365277X.2010.01054.x

16. Whitaker RC, Wright JA, Pepe MS, Seidel KD, Dietz WH. Predicting obesity in young adulthoo from childhood and parental obesity. N Engl J Med 1997;337(13):869-873. [http://dx.doi.org/10.1056 NEJM199709253371301

17. Jinabhai CC, Taylor M, Sullivan KR. Implications of the prevalence of stunting, overweight and obesity amongst South African primary school children: A possible transition. Eur J Clin Nutr 2003;57(2):358365. [http://dx.doi.org/10.1038/sj.ejcn.1601534]

Accepted 22 August 2014. 